\title{
Fouling of Nanofiltration Membranes
}

\author{
Flávio Caldeira Silva \\ Additional information is available at the end of the chapter \\ http://dx.doi.org/10.5772/intechopen.75353
}

\begin{abstract}
Despite all promising perspectives and new research in nanofiltration, for example, in drinking water production, in wastewater treatment, the food industry, the chemical and pharmaceutical industry, and many other industries, there are still some obstacles that slow down large-scale applications. Fouling is an irreversible and time-dependent phenomenon, and it is related to the characteristics of the membrane and solute-solute and solute-membrane interactions. Therefore, an understanding of fouling mechanisms such as fouling characteristics and consequences, fouling mathematical models, and physicalchemical and processing factors affecting fouling, are very important. As a result, the aim of this chapter is to present some phenomena that contribute to fouling: physicalchemical interactions, pore mechanical blocks, and deposit of suspension material on membrane surface.
\end{abstract}

Keywords: nanofiltration, fouling, fouling membranes, fouling characteristics, membrane process

\section{Introduction}

Nanofiltration (NF) is defined as "a process intermediate between reverse osmosis and ultrafiltration that rejects molecules which have a size in the order of one nanometer." In general, the use of membrane process is limited by fouling, which reveals itself as a decrease in flux with time of operation. Fouling probably is the most important reason for the minimal acceptance of nanofiltration and other membrane processes in large-scale processing [1, 2].

A number of factors contribute to fouling and are strongly interlinked. Organic, inorganic, particulate, and biological fouling are some of the main fouling categories. Also important are metal complexes, for example, $\mathrm{Fe}, \mathrm{Al}, \mathrm{Si}$. Despite many research traditionally focusing on one 
category or fouling mechanism at a time, it is well accepted that in most cases, it is not one single category that can be identified. In most real-life applications, all four types of fouling go hand in hand $[2,3]$. Fouling is an irreversible and time-dependent phenomenon; it is related to the characteristics of the membrane and solute-solute and solute-membrane interactions that cause an irreversible decline in the flow of permeate, which can only be recovered by the chemical cleaning of the membrane. In addition, some process parameters like equipment design, temperature, feed concentration, flow, and pressure can also contribute to membrane fouling.

\section{Nanofiltration and membranes}

The singularity of these membranes is highlighted by their ability to selectively reject different dissolved salts; they have a high rejection rate of low molecular weight, dissolved components. Nanofiltration membranes with low transmembrane pressure, operating pressure of generally 5-30 bar, were developed to achieve high divalent ion rejection. It is expected that the rejected molecules can have a molecular weight of $200 \mathrm{~g}$. $\mathrm{mol}^{-1}$; this corresponds to an equivalent of Stokes diameter of approximately $1 \mathrm{~nm}[3,4]$.

Nanofiltration membranes are neither entirely dense nor entirely porous, so their retention mechanisms are determined by both size exclusion (porous membranes) and sorption and diffusion (dense membranes). Also, these kinds of membranes are principally used to partially soften potable water, allowing some minerals to pass into the product water, thus increasing the stability of the water and preventing it from being aggressive to distribution piping material. Additionally, NF membranes are discovering increasing use in purifying industrial effluents and minimizing waste discharge. The key to using NF membranes for particular applications is the selection of a membrane with the appropriate rejection characteristics and the design of a suitable process. In general, NF membranes are characterized by a high charge density and pore sizes in the range of nanometers; the surface charge is most often negative and has the greatest effect on the selective passage nature of these membranes. New studies have been developed, and new membranes having unique properties, including a varying range of hardness rejection and fouling resistance manufactured $[2,4]$.

\section{Characteristics of fouling and consequences of fouling}

The efficiency of the nanofiltration process is affected by fouling on the membrane and other factors like tangential velocity, pressure, temperature, turbulence, feed particles size, concentration polarization changes in membrane properties, and membrane characteristics [2].

Fouling phenomenon is the result of the interaction between solutes adsorbed onto the membrane and solutes present in the feed flow, or even between the membrane and diverse solutes present in the solution. Fouling can be the result of three main factors or the interaction 
between them: the properties of the material constituting the membrane, the properties of the solute, and the operational parameters $[2,3,5]$.

The interaction between solute and membrane, the interaction among molecules of solute present, and the chemical constitution of the membrane structure must be identified to understand the phenomenon of fouling. Notably, the interaction between solute and membrane will determine the fouling formed by the adsorption of solute onto the membrane surface $[6,7]$.

In contrast to polarization of concentration, which is considered a reversible phenomenon and independent of process time, fouling is an irreversible phenomenon and dependent on time. Fouling can be defined as a deposition or adsorption of retained particles, colloids, macromolecules, salts, etc., on the membrane surface and/or aggregation in the pores, causing partial or even total blockage of the pores, resulting in a continuous decline of flow. The different ways in which the pores become blocked are a function of the size and form of the solute in relation to the pore size distribution of the membrane. Partial blockage of the pores occurs when isolated macromolecules or groups of them partially seal the pores, with the possibility of forming a deposit on the membrane surface, increasing the resistance to permeation. When chemical species are deposited or adsorbed on the inside of the membrane pores, it reduces the volume available for passage of the permeate; there is internal blockage of the pores. Complete blockage of the pores occurs when the particles that deposit on the membrane surface are larger than the membrane pores, completely obstructing them $[8,9]$.

This phenomenon, related to the characteristics of the membrane and solute-solute and solute-membrane interactions, causes an irreversible decline in the flow of permeate, which is only recovered by the chemical cleaning of the membrane. Figure 1 shows some types of blocks $[2,8,9]$.

Observing and analyzing Figure 1, it is possible to understand the different ways in which the membrane can be blocked and compare concentration polarization. When hydrocolloids, macromolecules, or other particles with larger dimensions as compared to the diameter of the membrane pore, are rejected and accumulate on the surface of the membrane, concentration polarization occurs. An increase in resistance to solvent passage occurs by this accumulation, and consequently leads to a greater local osmotic pressure. In general, concentration polarization occurs in any selective transport process such as classical filtration and tangential filtration. In tangential flux, concentration polarization stabilizes quickly and this provokes an additional resistance to mass transfer by the membrane, and as a result a decline in flux permeate $[10,11]$.

The precipitation of organic solutes on the membrane surface is known as gel formation. This process usually occurs when the wall concentration due to concentration polarization exceeds the solubility of the organic solute. It is very important to consider that gel formation does not necessarily mean irreversible flux decline. The gel polarization model is based on the fact that at steady state, flux reaches a limiting value, where an increase in pressure no longer increases the flux. Conforming to the gel polarization model, at this limiting value, the solubility limit of the solute in the boundary layer is reached and a gel formed $[5,12]$. 
(A)

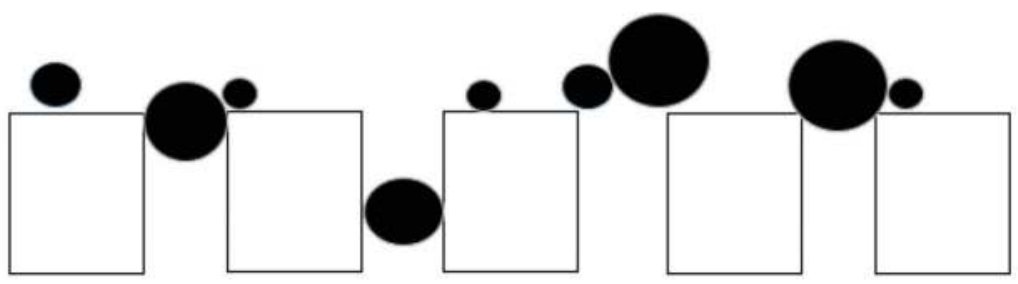

(B)

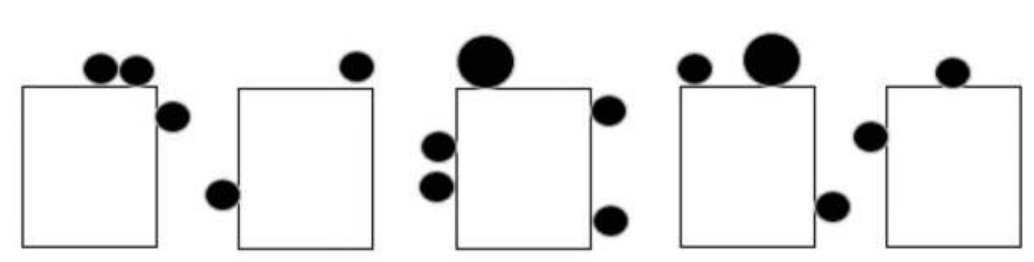

(C)

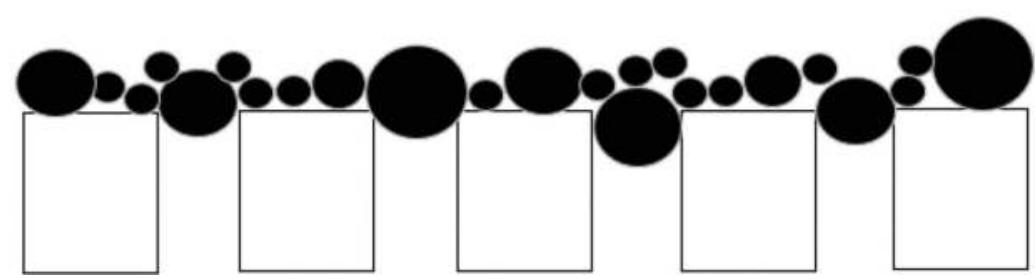

Figure 1. Inlay membrane mechanism: (A) complete blockage of pores; (B) partial (internal) blocking of pores; (C) polarized layer.

The typical permeation flux curves can be described in three different stages. The first stage (I) is characterized by a sudden drop in flux in the first minutes due to the polarization of the solutes by concentration on the surface of the membrane. At this stage, loss of flow is reversible. In the second stage (II), the flow variation decreases, varying with the pore diameter of the membrane. The precipitation of the accumulated solutes begins, which leads to the blocking of the pores and the adsorption of the components in the membrane, causing the formation of the polarized layer and the incrustation. The decrease in flow due to this latter phenomenon is irreversible. Finally, the third stage (III) is the consolidation of incrustation; in this stage, the flow decreases continuously and slowly. Figure 2 shows each step described here [13].

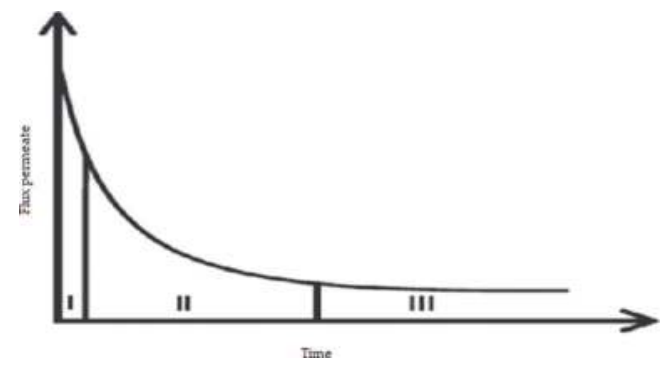

Figure 2. Typical permeation flux curves described in three different stages (adapted from Marshall and Daufin [13]). 


\section{Physical and chemical factors affecting fouling}

Nanofiltration membranes retain substances with molar masses higher than $\sim 300 \mathrm{~g} \mathrm{~mol}^{-1}$ and multivalent ions. The retention characteristics depend largely on how much free volume there is in the membranes, which can for some membranes be related to the flux. As nanofiltration membranes have characteristics of both ultrafiltration as well as reverse osmosis membranes, their fouling characteristics are also rather unique [12, 14].

It has already been discussed that fouling is initiated by solute-membrane material interactions; however, Van der Waals forces, chemical binding, and Lewis acid-base interactions are the major phenomena involved in the interactions resulting between surfaces and solutes on a molecular level. As a result, physicochemical properties of membrane surfaces are changed and this facilitates the deposition of other molecules and other aggregates. Membrane-solvent interactions can be expected to diversify with changes in the solvent properties, such as molecular size, surface tension, viscosity, and dielectric constant $[11,14,15]$.

The relationship between the type of solvent, polar or non-polar, and the type of membrane, hydrophilic or hydrophobic, used in separation processes, must be judiciously analyzed. The flow rate of polar solvents is significantly higher (8-10 times) than that of non-polar solvents in processes carried out with hydrophilic membranes [9].

The relationship between the components of solute molar mass and rejection by the membrane can be observed from the results obtained in the analysis of the rejection of triacylglycerols present in $n$-hexane solution, where the percent rejection obtained was higher for larger molar masses [9].

Fouling of nanofiltration membranes has been studied very extensively up to date and many studies have tried to explain what happens in each situation. Because fouling can decrease the flux drastically, it is important to investigate what types of foulants should be avoided in NF [13].

It is necessary to identify the foulants in order to reduce or eliminate fouling. This objective can be achieved by a characterization of the fouled membrane or by fouling studies in the laboratory. Once the foulants are identified, suitable control strategies can be adapted. An overview of foulants and appropriate control strategies are summarized in Table 1. The strategies include a number of categories, for example: module design, operation mode and cleaning, membrane selection like non-fouling materials/coatings, feed pre-treatment, suitable surface charge, porosity, hydrophilicity chlorine compatibility, and surface roughness [5, 11].

Important factors that differentiate nanofiltration from other processes of membranes separation are as follows:

- Rejection of multivalent negative ions, such as sulfates, and phosphates;

- Rejection of sodium chloride (0-70\%) in systems of complex mixtures;

- Rejection of particles without loads, dissolved materials, and positive charge ions in solution is related to the size and shape of the molecule in question. 


\begin{tabular}{ll}
\hline Foulant & Fouling control \\
\hline General & Hydrodynamics/shear, operation below critical flux, chemical cleaning \\
$\begin{array}{l}\text { Inorganic } \\
\text { (scaling) }\end{array}$ & $\begin{array}{l}\text { Operate below solubility limit, pre-treatment, reduce } \mathrm{pH} \text { to } 4-6 \text { (acid addition), low recovery, } \\
\text { additives (antiscalants); some metals can be oxidized with oxygen }\end{array}$ \\
Organic & $\begin{array}{l}\text { Pretreatment using biological processes, activated carbon, ion exchange, ozone, enhanced } \\
\text { coagulation }\end{array}$ \\
$\begin{array}{l}\text { Colloids } \\
(<0.5 \mu \mathrm{m})\end{array}$ & $\begin{array}{l}\text { Pre-treatment using coagulation and filtration, microfiltration, ultrafiltration } \\
\text { Biological solids }\end{array}$ \\
$\begin{array}{l}\text { Pretreatment using disinfection (e.g., chlorination/dechlorination), filtration, coagulation, } \\
\text { microfiltration, ultrafiltration }\end{array}$ \\
\hline Adapted and modified from Fane et al. [19].
\end{tabular}

Table 1. Foulants and their control strategies in nanofiltration processes.

Therefore, the efficiency of a nanofiltration process depends on the size of the particles present in the solution and molecular loads [5].

It is also known that mineral salts have a deep influence on the fouling of ultrafiltration and nanofiltration membranes. These components can interact with the membrane directly or precipitate on the membrane and cause a reduction in flux. However, mineral salts contribute to the ionic strength of the solution, which in turn affects the conformation and dispersion of the proteins and consequently, the fouling of the nanofiltration membrane $[2,5,6]$.

Many studies report the effect of $\mathrm{pH}$ on membrane fouling. Flux is lowest at the isoelectric point of the protein and is higher as the $\mathrm{pH}$ moves away from the isoelectric point. Changes in $\mathrm{pH}$ affect proteins in solubility, which is generally lowest at the isoelectric point and increases as $\mathrm{pH}$ is adjusted away from it; conformation, because of the interaction between proteins and membranes, also changes with $\mathrm{pH}$ membranes. Thus, these effects of $\mathrm{pH}$ on flux should not be unexpected, especially in view of the effect on solubility of salts $[2,6]$.

In general, in many industrial or laboratory test processing cases, membrane fouling may be caused by pectins, proteins, tannins, starch, cellulose, and hemicellulose. Moreover, it is very necessary to consider biofouling in membranes. Biofouling is a term used to describe all instances of fouling where biologically active organisms are involved. Whilst the different forms of chemical fouling reflect largely passive deposition of organic or inorganic materials on membrane surfaces, biofouling is a dynamic process of microbial colonization and growth, which results in the formation of microbial biofilms. Biofilms are microbial communities that grow attached to surfaces. Biofilm formation constantly precedes biofouling, which becomes an issue only when biofilms reach thicknesses and surface coverages that reduce permeability. In some cases, biofilms may cause total blockage of feedwater channels and mechanical collapse of modules by telescoping [2, 6, 15-22]. 


\section{Processing factors affecting fouling: temperature, pressure, feed concentration, flow rate and turbulence}

It is important to consider that other factors can affect fouling, and not just the complex physical-chemical interaction of feed components.

The main physical operational parameters that affect the permeate flow rate are: pressure, temperature, viscosity and density of the feed fluid, and the tangential velocity [23].

The temperature effect is not completely clear and can influence fouling in two different ways. It is possible that as temperature is increased further, the beneficial effects (lower viscosity, higher diffusivity) will outweigh the harmful effects (loss of solubility of salts) and may result in a net increase in flux. It could also result in a decrease in flux for certain feeds, due to decreases in solubility of feed components at higher temperatures. Evidently, for biological systems, too high temperature will result in protein denaturation and other heat damage, which will provoke lowering of the flux $[2,10]$.

An increase in feed concentration alters the viscosity, density, and diffusivity of the feed solution, causing a decrease in permeate flow rate. The permeate flow rate is directly proportional to the pressure applied and inversely proportional to the viscosity. Viscosity can be controlled by two factors: solids concentration in the feed and temperature [24, 25].

As is known, an increase in pressure results in a greater convective rate for the transport of solute to the membrane surface, increasing its concentration at the interface, causing an increase in diffusivity of the solute in the opposite direction to that of the process pressure, and thus decreasing the permeate flow rate [26-29]. It is important to emphasize that there is a linear relationship between flow rate and the inverse of the solvent viscosity for nanofiltration and ultrafiltration membranes, revealing that the main mass transport mechanism in these systems is convection $[2,30]$.

Moreover, an increase in tangential velocity increases the permeate flow rate by provoking greater turbulence, causing a dispersion in the solute molecules concentrated on the membrane surface, and reducing the thickness of the gel layer. High shear rates generated at the membrane surface tend to shear off deposited material thus reducing the hydraulic resistance of the fouling layer. This is one of the simplest and most effective methods to control the effect of concentration polarization. Severe decreases in flux can sometimes be observed at too low velocities $[2,6,31]$.

\section{Resistance and mathematical models of fouling}

Because of concentration polarization and fouling, there is a reduction on flux permeate value compared with pure solvent. As a result, both represent additional resistances to mass transfer by the membrane. The kinetic that is relativity slow for some phenomes and that provokes 
fouling, can explain the long time it takes to reach a possible stationary state. Figure 3 is presented as an illustration of these phenomes. Thus, the relation between permeate flux and pressure variation applied on both sides of the membrane can be expressed by Eq. (1):

$$
J=\frac{1}{n R_{T}} \Delta P
$$

where

$$
R_{T}=R_{m}+R_{a}+R_{b}+R_{g}+R_{c p}
$$

Here $R_{m^{\prime}}$ resistance of transport by the membrane; $R_{a^{\prime}}$ additional resistance due to adsorption phenomenon; $R_{b^{\prime}}$ additional resistance of physical pores blocks; $R_{g^{\prime}}$ additional resistance due to formation of gel layer on the membrane surface; $R_{p c}$ additional resistance due to polarization concentration phenomenon; $R_{T}$, total resistance due of mass transfer through the membrane; $n$, solution viscosity that permeates through the membrane.

Despite the resistance-in-series model being used frequently, in which permeation flux declines due to membrane fouling and concentration polarization resistance on the membrane surface, other mathematical models to predict the flux behavior can also be used. A number of mathematical models are available in the literature that attempt to describe the mechanism of transport of particles through membranes such as Brownian diffusion, inertial lift, shear-induced diffusion, flowing cake and surface transport, and cake layer models [32].

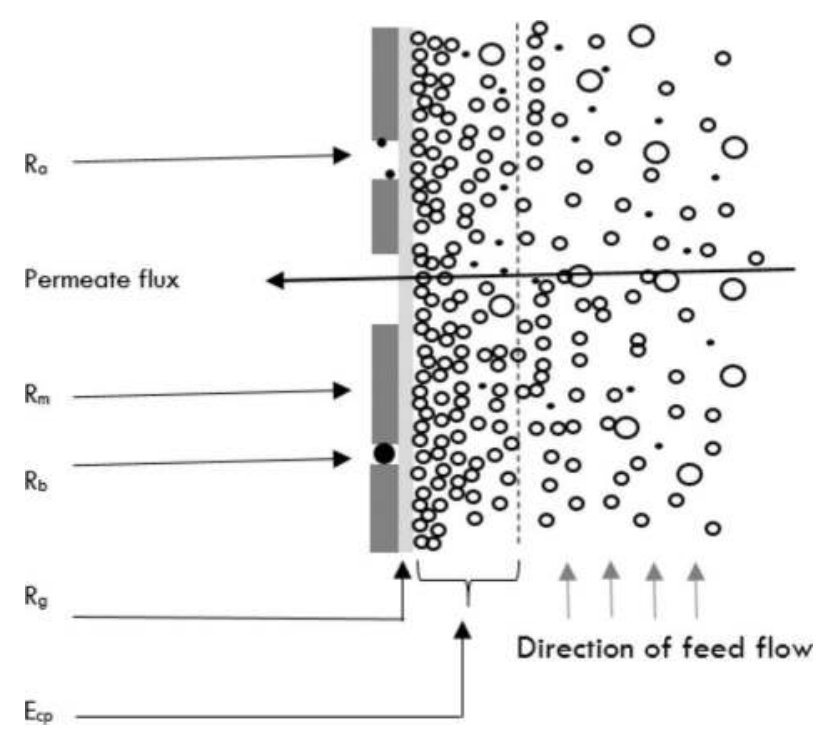

Figure 3. Resistances of mass transfer in membrane provoked by fouling and concentration polarization. Additional resistance: $R_{m^{\prime}}$ membrane resistance; $R_{a^{\prime}}$ adsorption; $R_{b^{\prime}}$ blocked pore; $R_{g^{\prime}}$ gel layer; $E_{c p^{\prime}}$ concentration polarization. 
The most elementary type of model relates the flux to the time and volume permeated. Most of them are based on the assumption that the build-up of fouling layer is a first order reaction [2].

Decrease in permeate flux with time has been related to the volume concentration factor $(\mathrm{VCR})$, defined as the initial volume divided by the retentate volume at any time ( $\mathrm{VCR}=V_{0} /$ $\left.\left(V_{0}-V_{P}\right)\right)$, where $V_{0}$ is the initial volume and $V_{P}$ is the permeate volume [33].

In general, almost any data (flux vs. time) will adequately fit almost any of models reasonably well, but since they are semi-empirical in nature, they do not help to explain or understand the phenomenon itself [2].

\section{Fouling and cleaning}

According to the characteristics and factors described before, fouling reveals itself to be a decline performance, commonly a decline in flux under constant operating conditions, processing, and probable modification in the permeate properties of the membrane. The optimum way to reduce fouling will depend on the fouling process [34].

Membrane fouling problems can also be cleaning problems. For food processes, the membrane material, and all other food contact surfaces, should be compatible with normal food and food cleaners $[2,34]$.

Reducing membrane fouling must include an attention to the chemical nature of the membrane such as physical-chemical properties of feed stream. Some studies reported that hydrophilic membranes normally foul less than hydrophobic membranes [34].

To decide about the cleaning process, it is very important to consider the type of foulant, that is, the cleaning agents to use will depend on the material that causes the fouling. Moreover, the cleaning cycle can be incorporated into the design of nanofiltration plant as automatic cleaning operation. The membrane system is considered clean when the original water flux has been restored [2].

\section{Final considerations}

Nanofiltration technology has been widely applied in the desalination and concentration, separation and purification of drinking water, wastewater treatment and other industrial processes [36-41]. This process already plays an important role in a variety of cases in the water treatment, the dairy industry, biomedical processes and, so on. It is important to note that the ability of nanofiltration to separate monovalent and multivalent ions is a key feature in environmentally related processes. Operations with high pressure membranes are already established technologies for the treatment of waste water that aim at the production of purified water for recycling or reuse and recovery of valuable compounds [12, 35, 42-46].

Among these example applications, a number of factors have been contributing to the increasing interest in using membrane processes for water treatment. The essential factor is the 
stringent water quality regulations, which can be met to some extent, in an economically viable way, by membrane processes [5].

Furthermore, the food industry was one of the first industries to introduce membrane filtration into its commercial processes since membrane processes are potentially nondestructive, relatively energy efficient (no phase change), and even cheaper than conventional treatment [36-41]. However, nowadays, the cost of application and industrial processes by membranes is still expensive.

Researches reveal that in practice, industrial application of membranes becomes more attractive and competitive when combined processes, i.e., classical processes and membrane processes, are used together. In this way, each process acts in the most efficient part, and thus, the results are more advantageous than when applying technologies alone [5].

It is also necessary to improve the competitiveness of the process for filtration of drinking water, wastewater treatment, the food industry, the chemical and pharmaceutical industry, purification of biodiesel, and many other industries. It is important to improve the technological process and products and to reduce costs.

Fouling of membranes is important as it limits the competitiveness of the process due to an increase in costs caused by an increased energy demand, additional labor for maintenance and chemical costs for cleaning as well as a shorter lifetime of the membranes. Essential for effective fouling control is a proactive operation of the nanofiltration (NF) plant where an early indication of fouling is acted upon and a good identification of the type of fouling is carried out. On the other hand, nanofiltration technology can be applied in many industrial sectors in many different ways. The use of membrane technology appears as a relevant alternative to conventional processing in a huge variety of annexed processes.

NF membranes are also finding increasing use for purifying industrial effluents and minimizing waste discharge. The possibility of waste treatment, the preservation of compounds of importance from them, the reduction in energy consumption and of chemical products stand out among the principal advantages of NF membranes.

\section{Author details}

\section{Flávio Caldeira Silva}

Address all correspondence to: flaviocaldeira@iftm.edu.br

Instituto Federal do Triângulo Mineiro, MG, Brazil

\section{References}

[1] Ogawa N, Kimura K, Watanabe Y. Membrane fouling in nanofiltration/reverse osmosis membranes coupled with a membrane bioreactor used for municipal wastewater treatment. Desalination and Water Treatment. 2010;18:292-296 
[2] Cheryan M. Ultrafiltration and Microfiltration Handbook. Chicago: Technomic Publ; 1998

[3] Broeckmann A, Wintgens T, Schätfer AI. Removal and fouling mechanisms in nanofiltration of polysaccharide solutions. Desalination. 2005;178:149-159

[4] Bartels C, Wilf M, Casey W, Campbell J. New generation of low fouling nanofiltration membranes. Desalination. 2008;221:158-167

[5] Schäfer AI, Fane AG, Waite TD. Nanofiltration-Principles and Applications. Great Britain: Elsevier; 2006

[6] Strathmann H. Synthetic membranes and their preparation. In: Porter MC, editor. Handbook of Industrial Membrane Technology. New Jersey: Noyes Publications; 1990

[7] Susanto H, Ulbricht M. Influence of ultrafiltration membrane characteristics on adoptive fouling with dextrans. Journal of Membrane Science. 2005;266:132-142

[8] Mulder MHV. Polarization phenomena and membrane fouling. In: Noble RD, Stern SA, editors. Membrane Separations Technology: Principles and Applications. Amsterdan: Elsevier; 1995. pp. 45-84

[9] Bhanushali D, Kloos S, Bhattacharyya D. Solute transport in solvent resistant nanofiltration membranes for non-aqueous systems: Experimental results and the role of solutesolvent couplin. Journal of Membrane Science. 2002;208:343-359

[10] Giorno L, Todisco S, Donato L, Driolo E. Study of fouling phenomena in apple juice clarification by enzyme membrane reactor. Separation Science and Technology. 1998; 33:739-756

[11] de Morais Coutinho C, Chiu MC, Basso RC, Badan Ribeiro AP, Gonçalves LAG, Viotto LA. State of art of the application of membrane technology to vegetable oils: A review. Food Research International. 2009;42(5-6):536-550

[12] Halbert AC, Borges CP, Nóbrega R. Processos de separação com membranas. Rio de Janeiro: Ed. e-papers; 2006. p. 180

[13] Marshall AD, Daufin G. Physico-chemical aspects of membrane fouling by dairy fluids. In: IDF Special Issue 9504 (Ed.), Fouling and Cleaning in Pressure Driven Membranes Process. Brussels: International Dairy Federation; 1995. pp. 9-29

[14] Nyström M, Kaipia L, Luque S. Fouling and retention of nanofiltration membranes. Journal of Membrane Science. 1995;98:249-262

[15] Hafidi A, Pioch D, Ajana H. Adsorptive fouling of inorganic membranes during microfiltration of vegetable oils. European Journal of Lipid Science and Technology. 2003;105:138-148

[16] Scott K. Handbook of Industrial Membranes. Introduction to Membranes Separations. Vol. 1. Oxford, UK: Elservier. Cap; 1995. pp. 3-175

[17] Kim I, Kim J, Lee K, Tak T. Phospholipids separation (degumming) from crude vegetable oil by polyimide ultrafiltration membrane. Journal of Membrane Science. 2002;205:113-123 
[18] Lappin-Scott HM, Costerton JW. Bacterial biofilms and surface fouling. Biofouling. 1989;1:323-342

[19] Fane AG, Beatson P, Li H. Membrane fouling and its control in environmental applications. Water Science Technology. 2000;41(10-11):303-308

[20] Ridgway HF, Flemming HC. Membrane Biofouling, in Water Treatment Membrane Processes. In: Mallevialle J, Odendaal PE, Wiesner MR, editors. New York: McGraw Hill; 1996;6(1-6):62

[21] Flemming H-C. Biofouling Bei Membranprozessen. Berlin: Springer; 1995

[22] Sadr Ghayeni SB, Beatson PJ, Schneider RP, Fane AG. Adhesion of waste water bacteriato reverse osmosis membranes. Journal of Membrane Science and Technology. 1997;138:29-42

[23] Scott K. Handbook of Industrial Membranes. Oxford: Elsevier; 2003

[24] Satyanarayana SV, Bhattacharya PK, De S. Flux decline during ultrafiltration of Kraft black liquor using different flow modules: A comparative study. Separation and Purifcation Technology. 2000;20:155-167

[25] Hwang ST, Kammermeyer K. Membranes in separations. In: Cheryan M, editor. Ultrafiltration and Microfiltration Handbook. Chicago: Technomic Publ; 1998. p. 526

[26] Chen V, Fane AG, Madaeni S, Wenten IG. Particle deposition during membranes filtration of colloids: Transition between concentration polarization and cake formation. Journal of Membrane Science. 1997;125:109-122

[27] Field RW, Wu D, Howell JA, Gupta BB. Critical flux concept for microfiltration fouling. Journal of Membrane Science. 1995;100:259-272

[28] Porter MC. Handbook of Industrial Membrane Technology. New Jersey: Noyes Publications; 1990

[29] Song L. A new model for the calculation of the limiting flux in ultrafiltration. Journal of Membrane Science. 1998;144:173-185

[30] Tsui EM, Cheryan M. Characteristics of nanofiltration membranes in aqueous ethanol. Journal of Membrane Science. 2004;237:61-69

[31] Cheng T, Lin CT. A study on cross flow ultrafiltration with various membrane orientations. Separation Purification Technology. 2004;39:13-22

[32] Wang Z, Chu J-s, Wen-juan W, Yao J-m. Study of unsteady-state flux prediction in crossflow microfiltration. Desalination. 2009;238:290-301

[33] Mondor M, Girard B, Oresoli CM. Modeling flux behavior for mebrane filtration of apple juice

[34] Heldman DR, Lund DB. Handbook of Food Engineering. 2nd ed. Boca Raton, FL: CRC Press; 2007 
[35] Wang XL, Zhang $\mathrm{CH}$, Ouyang PK. The possibility of separating saccharides from a $\mathrm{NaCl}$ solution by using nanofiltration in diafiltration mode. Journal of Membrane Science. 2002;204:271-281

[36] Wang XL, Ying AL, Wang WN. Nanofiltration of L-phenylalanine and L-aspartic acid aqueous solutions. Journal of Membrane Science. 2002;196:59-67

[37] Li SL, Li C, Liu YS, Wang XL, Cao ZA. Separation of L-glutamine from fermentation broth by nanofiltration. Journal of Membrane Science. 2003;222:191-201

[38] Wang DX, Wang XL, Tomi Y, Ando M, Shintani T. Modeling the separation performance of nanofiltration membranes for the mixed salts solution. Journal of Membrane Science. 2006;280:734-743

[39] Wang DX, Wu L, Liao ZD, Wang XL, Ando M, Shintani T. Modeling the separation performance of nanofiltration membranes for the mixed salts solution with $\mathrm{Mg}^{2+}$ and $\mathrm{Ca}^{2+}$. Journal of Membrane Science. 2006;284:384-392

[40] Jiraratananon R, Sungpet A, Luangsowan P. Performance evaluation of nanofiltration membranes of nanofiltration membranes for treatment of effluents containing reactive dye and salt. Desalination. 2000;130:177-183

[41] Ducom G, Cabassud C. Interests and limitation of nanofiltration for the removal of voltaic organic compounds in drinking water production. Desalination. 1999;124:115-123

[42] Galanakis CM, Tonmerg E, Gekas V. Clarification of high-added value products from olive mill wastewater. Journal of Food Engineering. 2010;99:190-197

[43] Galanakis CM, Chasiotis S, Botsaris G, Gekas V. Separation and recovery of proteins and sugars from Halloumi cheese whey. Food Research International. 2014;65:477-483

[44] Muro C, Riera F, Del Carmen Diaz M. Membrane separation process in wastewater treatment of food industry. In: Valdez B, editor. Food Industrial Processes-Methods and Equipment. Rijeka, Croatia: InTech; 2012. pp. 253-280

[45] Suárez E, Lobo A, Alvarez-Blanco S, Riera FA, Álvarez R. Utilization of nanofiltration membranes for whey and milk ultrafiltration permeate demineralization. Desalination. 2006;199:345-347

[46] Tylkowski B, Tsibranska I, Kochanov R, Peev G, Giamberini M. Concentration of biologically active compounds extracted from Sideritis ssp. L. by nanofiltration. Food and Bioproducts Processing. 2011;89:307-314 
